\title{
A New Three-Phase Space-Vector-Modulated Power Factor Corrector
}

\author{
Rong-Jie Tu \\ Power Electronics Lab. \\ Department of Electrical Engineering \\ National Taiwan University \\ Taipei, Taiwan \\ Chern-Lin Chen \\ Chern-Lin Chen

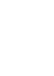

\begin{abstract}
A new three-phase three-wire boost-type power factor corrector (PFC) which draws sinusoidal input currents in phase with the corresponding input phase voltages is proposed and analyzed in this paper. In the proposed topology, three $\mathrm{AC}$ switches are placed before the bridge rectifier and respectively across two power lines. A novel control scheme combining space-vector modulation and hysteresis current control is presented. Sinusoidal input line currents are observed in simulations.
\end{abstract}

\section{INTRODUCTION}

Off-line switch-mode $\mathrm{AC} / \mathrm{DC}$ and $\mathrm{AC} / \mathrm{DC} / \mathrm{AC}$ power converters have historically employed full-wave bridge rectifiers and bulk capacitor filters to power the unregulated DC buses. The input line current is a narrow pulse with rich harmonics resulting in poor power factors. This dramatically increases the utility transmission power losses and causes harmonics pollution of power lines. Moreover, larger rating power devices must be used to encounter the higher peak currents. Consequently, active power factor correctors (PFC) have gained increasing interests of research recently for improving the power factor deterioration.

The PFC's can be classified into two groups: single-phase PFC's and three-phase PFC's. Owing to its simple control design and excellent performance, single-phase boost-type PFC's have made their popularity in applications where the power rating is small $(<2 \mathrm{~kW})[1,2]$. However, in large power applications, three phase boost-type PFC's with high power handling capability are dominant. Conventionally, a three-phase boost-type PFC [3,4 ] consists of six switches with anti-paralleled diodes as shown in Fig. 
two power lines. This unique feature makes both simple operation principle and control design possible. The operation principle with simulation verification is described in the following sections. A simple control strategy combining space-vector modulation and hysteresis current control is presented. No microprocessor is used in the proposed control scheme.

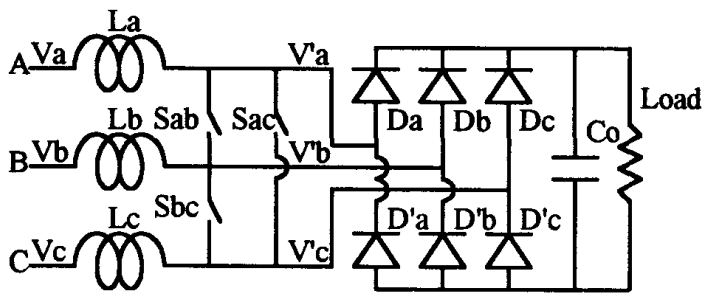

Fig. 2. Proposed three-phase boost-type power factor corrector.

\section{PROPOSED POWER FACTOR CORRECTION TOPOLOGY}

Fig. 2. illustrates the proposed three-phase three-wire boost-type power factor corrector. In this approach, conventionally used six switches are replaced by three delta-connected $\mathrm{AC}$ ones each across two power lines respectively located between the boost inductors and bridge rectifier. This unique feature makes both operational principles and control design simple. The AC switches, which block bi-directional voltages when opened and conduct bi-directional currents when closed, can be constituted by commercial power MOSFET's [8]. It's valuable to mention that the delta-connected $\mathrm{AC}$ switches need no dead-time consideration which is important in conventional approach for the cascade-connected switches across the output DC bus.

To explain the principles of operation and to derive the control scheme, the input phase voltages are divided into six 60-degree intervals in which no sign change occurs. In each interval, only two of the three inductor currents with the same sign are controlled. Take one of the six interval where $V a$ and $V b$ are positive and $V c$ is negative for example, only $I a$ and $I b$ are controlled. Sab is set normally open resulting in the subtopology in Fig. 3. According to the switching states of $S c a$ and $S b c$, there are four modes of operation in the example interval.

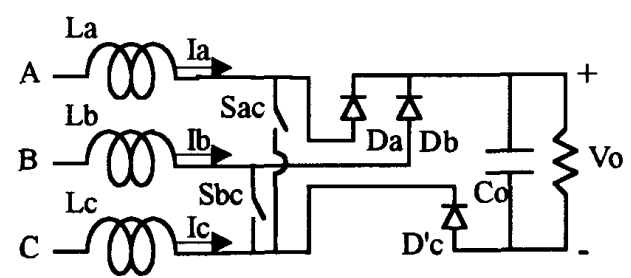

Fig. 3. Equivalent subtopology of the proposed three-phase PFC in the example interval where $V a$ and $V b$ are positive and $V c$ is negative.

Mode 1.) $S c a \mathrm{ON}, S b c$ ON.

As shown in Fig 4(a), $V a$ and $V b$ are connected to $\mathrm{Vc}$ are short circuit through the boost inductors. Currents flow from phase A and B, through the switches, to phase C. All the six diodes are reverse biased. The bulk capacitor discharges and supplies current to the load. $I a$ and $I b$ increase.

Mode 2.) $S c a$ ON, $S b c$ OFF.

As shown in Fig. 4(b), $I b$ flows through the diodes $D b, D^{\prime} c$ and back to phase $\mathrm{C}$, charging the output capacitor and powering the load. Diodes $D b$, and $D^{\prime} c$ are forward biased. Phase $\mathrm{A}$ and $\mathrm{C}$ are shorted through the inductors $L a$ and $L c$. $I a$ increases and $I b$ decreases.

Mode 3.) $S c a$ OFF, $S b c$ ON.

As shown in Fig. 4(c), mode 3 is similar to Mode 2, except that phase $\mathrm{A}$ and $\mathrm{B}$ are exchanged. Diodes $D a$, and $D^{\prime} c$ are forward biased. $I b$ increases and $I a$ decreases.

Mode 4.) $S c a$ OFF, $S b c$ OFF.

As shown in Fig 4(d), both phases A and B are connected to the positive terminal of the output capacitor. Ia and $I b$ flow through the diodes, charge the output capacitor and supply the load current. $I a$ and $I b$ decrease.

By selecting proper operation modes to shape the inductor currents, sinusoidal input currents in phase with the input voltages can be acquired. Next section describes the selection of appropriate operation modes by the space vector concept.

\section{SPACE VECTOR MODULATION}




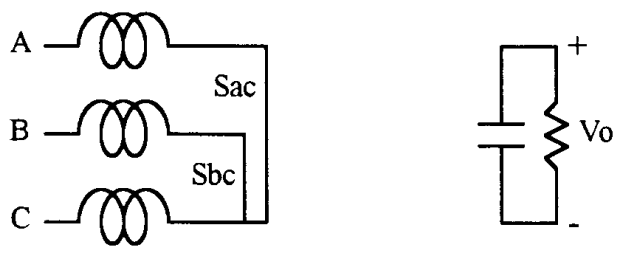

(a) mode 1

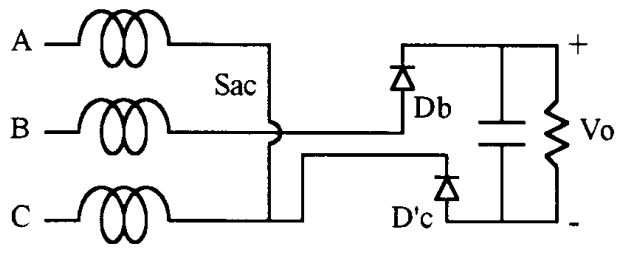

(b) mode 2

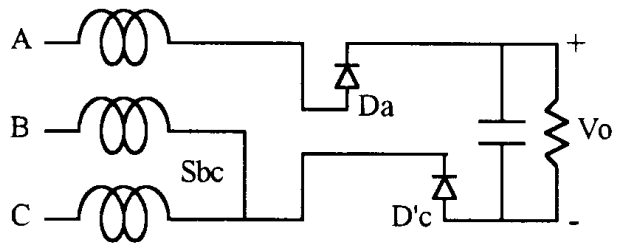

(c) mode 3

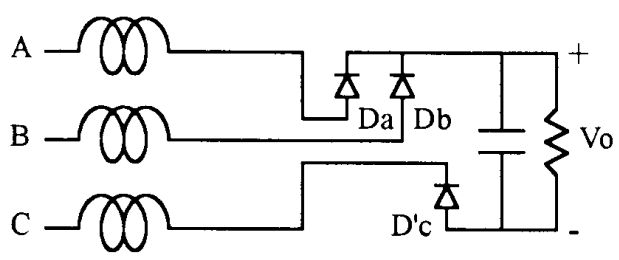

(d) mode 4

Fig. 4. Modes of operation in the example interval where $\mathrm{Va}$ and $V b$ are positive and $V c$ is negative.

With the concept of space vector, it is convenient to represent three-phase quantities $f a, f b$, and $f c$ (voltages or currents) as a space vector:

$f=f a+f b \times \alpha+f c \times \alpha^{2}$

where $\alpha=e^{j 2 / 3 \pi}$

The voltages before the bridge rectifier, $V^{\prime} a, V^{\prime} b$, and $V^{\prime \prime} C$, are functions of the corresponding 60-degree interval and the switch states, ON or OFF. Take mode $3 \&$ 4 for examples. In mode 3, from Fig. 4(c) it can easily be derived that $V^{\prime} a=2 / 3 \cdot V$, and $V^{\prime} b=V^{\prime} c=-1 / 3 \cdot V$, resulting in

$$
V^{\prime}=2 / 3 \cdot V o+(-1 / 3 \cdot V o) \cdot \alpha+(-1 / 3 V o) \cdot \alpha^{2}
$$

In mode $4, V^{\prime} a=V^{\prime} b=1 / 3 \cdot V$, and $V^{\prime} c=-2 / 3 V$,

$$
\begin{aligned}
V^{\prime} & =1 / 3 \cdot V o+1 / 3 \cdot V o \cdot \alpha+(-2 / 3) \cdot V o \cdot \alpha^{2} \\
& =V o \cdot e^{j 2 / 3 \pi}
\end{aligned}
$$

According to the operation modes, four space voltage vectors can be generated in the study interval where $V a$ and $V b$ are positive and $V c$ is negative. Illustrated in Table 1 are the possible voltage vectors in this interval, where " 1 " represents "ON", "0" represents "OFF", and " $x$ " represents "normally open". There are totally 24 vectors, but some of them are identical. As shown in Fig. 5, only seven distinct space voltage vectors can be generated. Table 2 gives the quantitative description of these generated vectors.

Table 1. Possible voltage vectors in the study interval.

\begin{tabular}{|c|c|c|c|c|}
\hline $\begin{array}{c}\text { (Sca,Sbc,Sab) } \\
\text { mode }\end{array}$ & $\begin{array}{c}(1,1, \mathrm{x}) \\
\text { mode 1 }\end{array}$ & $\begin{array}{c}(1,0, \mathrm{x}) \\
\text { mode 2 }\end{array}$ & $\begin{array}{c}(0,1, \mathrm{x}) \\
\text { mode 3 }\end{array}$ & $\begin{array}{c}(0,0, \mathrm{x}) \\
\text { mode 4 }\end{array}$ \\
\hline $\begin{array}{c}\text { voltage } \\
\text { vector }\end{array}$ & $\mathrm{V} 0$ & $\mathrm{~V} 3$ & $\mathrm{~V} 1$ & $\mathrm{~V} 2$ \\
$\mathrm{Vo}\left(e^{j / 3 \pi}\right)$ & $V o$ & $V o\left(e^{j 1 / 3 \pi}\right)$ \\
\hline
\end{tabular}

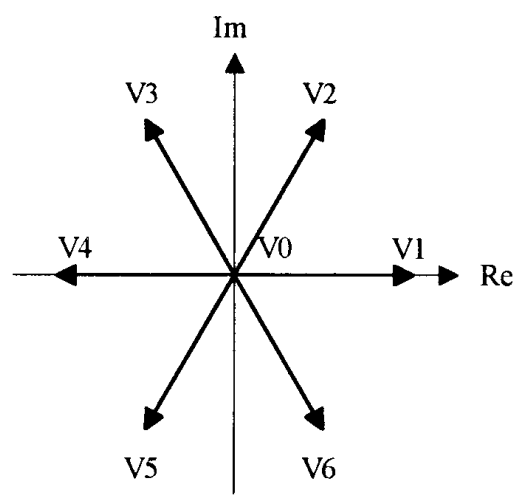

Fig. 5. Generated voltage space vectors. 
Table 2. Quantitative description of generated vectors.

\begin{tabular}{|c|c|}
\hline$\left.V^{\prime} a, V^{\prime} b, V^{\prime} c\right)$ & voltage vector \\
\hline$(2 / 3 \mathrm{Vo},-1 / 3 \mathrm{Vo},-1 / 3 \mathrm{Vo})$ & $V 1(V o)$ \\
\hline$(1 / 3 \mathrm{Vo}, 1 / 3 \mathrm{Vo},-2 / 3 \mathrm{Vo})$ & $\left.V 2 \mathrm{Vo}^{j / 3 \pi}\right)$ \\
\hline$(-1 / 3 \mathrm{Vo}, 2 / 3 \mathrm{Vo},-1 / 3 \mathrm{Vo})$ & $V 3\left(\mathrm{Vo}^{j / 3 \pi}\right)$ \\
\hline$(-2 / 3 \mathrm{Vo}, 1 / 3 \mathrm{Vo}, 1 / 3 \mathrm{Vo}))$ & $\left.V 4 \mathrm{Vo}^{j / 3 \pi}\right)$ \\
\hline$(-1 / 3 \mathrm{Vo},-1 / 3 \mathrm{Vo}, 2 / 3 \mathrm{Vo})$ & $\left.V 5 \mathrm{Vo}^{j / 3 \pi}\right)$ \\
\hline$(1 / 3 \mathrm{Vo},-2 / 3 \mathrm{Vo}, 1 / 3 \mathrm{Vo})$ & $\left.V 6 \mathrm{Vo}^{j / 3 \pi}\right)$ \\
\hline$(0,0,0)$ & $V 0(0)$ \\
\hline
\end{tabular}

Also, the input phase voltages and currents can be represented as a space vector:

$$
\begin{aligned}
& V=V a+V b \times \alpha+V c \times \alpha^{2} \\
& I=I a+I b \times \alpha+I c \times \alpha^{2}
\end{aligned}
$$

For a balanced three-phase AC source, the input voltage and current vector in the example interval can be rewritten as:

$$
\begin{aligned}
& V=V a\left(1-\alpha^{2}\right)+V b\left(\alpha-\alpha^{2}\right) \\
& I=I a\left(1-\alpha^{2}\right)+I b\left(\alpha-\alpha^{2}\right)
\end{aligned}
$$

The derivative of the current vector is

$$
d I / d t=\left(V-V^{\prime}\right) / L
$$

$\left(1-\alpha^{2}\right) \cdot d l a / d t+\left(\alpha-\alpha^{2}\right) \cdot d l b / d t$

$$
=\left\{\left[V a\left(1-\alpha^{2}\right)+V b\left(\alpha-\alpha^{2}\right)\right]-V^{\prime}\right\} / L
$$

where $L=L a=L b=L c$

The derivative of the current vector is a function of the operation modes (i.e. the voltage vector $V^{\prime}$ ) as illustrated in Table 3. The voltage vector $V^{\prime}$ determines the derivatives of the input current vector. Consequently, the input current waveforms can be controlled by selecting appropriate voltage vector $V^{r}$. Fig. 6 shows the waveforms of the input currents and the gate driving signal of $S c a$ and $S b c$ along with the corresponding voltage vectors in the example interval.
Table 3. The derivation of the current vector as a function of the operation modes.

\begin{tabular}{|c|c|c|c|c|}
\hline & mode 1 & mode 2 & mode 3 & mode 4 \\
\hline$L d I a / d t$ & $\begin{array}{c}V a \\
\text { (positive) }\end{array}$ & $\begin{array}{c}V a+1 / 3 V o \\
\text { (positive) }\end{array}$ & $\begin{array}{c}V a-I / 3 V o \\
\text { (negative) }\end{array}$ & $\begin{array}{c}V a-2 / 3 V o \\
\text { (negative) }\end{array}$ \\
\hline$L d I b / d t$ & $\begin{array}{c}V b \\
\text { (positive) }\end{array}$ & $\begin{array}{c}V b-2 / 3 V o \\
\text { (negative) }\end{array}$ & $\begin{array}{c}V b-1 / 3 V o \\
\text { (negative) }\end{array}$ & $\begin{array}{c}V b+1 / 3 V o \\
\text { (positive) }\end{array}$ \\
\hline
\end{tabular}

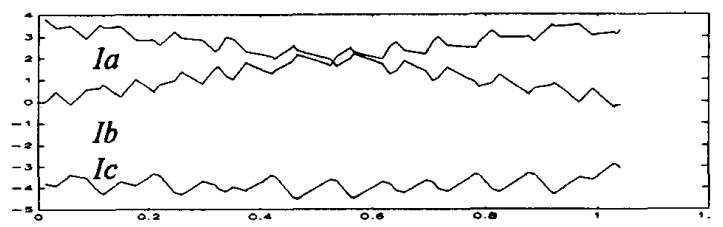

(a) input current waveforms

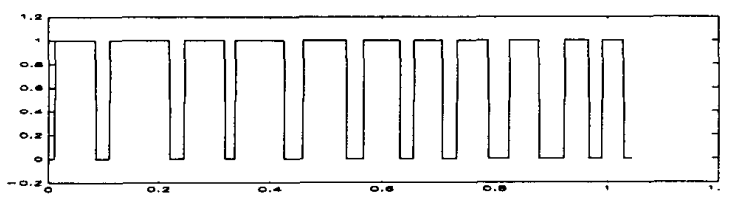

(b) gate driving signal of Sca

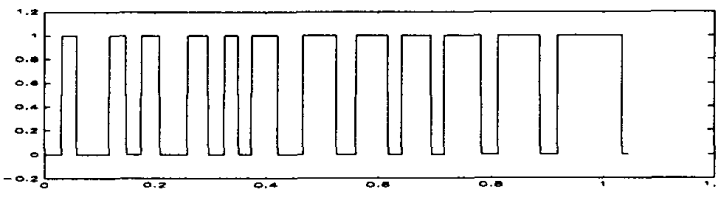

(c) gate driving signal of $S b c$

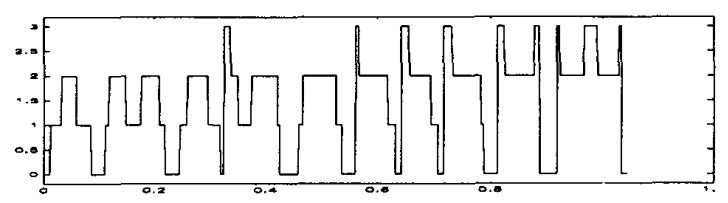

(d) corresponding voltage vector

Fig. 6. (a) Waveforms of the line current;, (b),(c) gate driving signals of $S c a$ and $S b c$ respectively; and (d) the corresponding voltage vectors in the example interval.

\section{CONTROL SCHEME}


A simple control strategy combining space-vector modulation and hysteresis current control for the proposed boost-type power factor corrector is designed. Fig. 7 shows the block diagram of the proposed control scheme. Current command $I^{*}$ is obtained by multiplying the corresponding input phase voltage and the error voltage $V e$ which is obtained from the voltage compensation loop. The input current is controlled to follow the input voltage waveform times the error voltage magnitude by selecting appropriate voltage vector $V^{n}$.

The desired voltage vectors are selected by the EPROM switching table outputs. The inputs to he EPROM consist of two group of signals: signs of the input voltages $S a, S b$, and $S c$ and the digital signals $d a, d b$, and $d c$ which are obtained by feeding the current errors $l e$ into the hysteresis comparators. The signs of the input voltages $S a$, $S b$, and $S c$ divide the input voltage into six 60-degree intervals (eight combinations exclusive of two nonexistent cases $(+,+,+)$ and $(-,-,-))$. The outputs of the hysteresis comparators determine the desired voltage vectors (i.e. operation modes) in the corresponding interval. However, for the simplicity of hardware design, the mapping between the voltage vectors and states of the $\mathrm{AC}$ switches is incorporated directly in the switching table as shown in Table 4.
The proposed three phase boost PFC with the control strategy combining the space vector modulation and hysteresis current control is simulated using PC Matlab. Fig. 8 illustrates the input line current waveforms. The hysteresis band width is exaggerated for clearness. Sinusoidal input currents in phase with the corresponding input voltage are observed. Also shown in Fig. 9 is the traces of the input current space vectors.

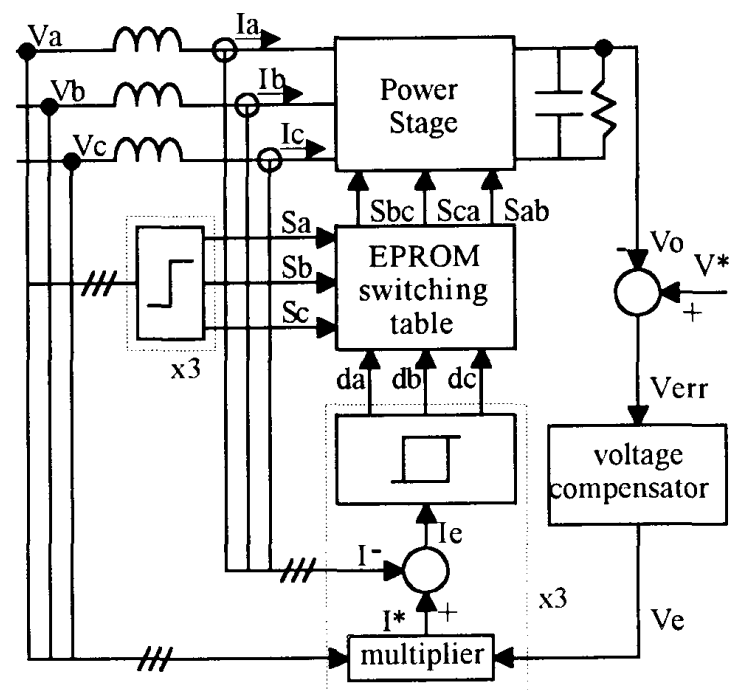

Fig. 7. Block diagram of proposed control strategy.

\section{RESULTS}

Table 4. Selections of states of switches $S b c, S c a$, and $S a b$.

\begin{tabular}{|c|c|c|c|c|c|c|c|c|}
\hline$(\mathrm{da}, \mathrm{db}, \mathrm{dc})$ & $(1,1,1)$ & $(1,1,0)$ & $(1,0,1)$ & $(1,0,0)$ & $(0,1,1)$ & $(0,1,0)$ & $(0,0,1)$ & $(0,0,0)$ \\
\hline$(+,+,-)$ & $\mathrm{V} 0$ & $\mathrm{~V} 0$ & $\mathrm{~V} 3$ & $\mathrm{~V} 3$ & $\mathrm{~V} 1$ & $\mathrm{~V} 1$ & $\mathrm{~V} 2$ & $\mathrm{~V} 2$ \\
& $(1,1,0)$ & $(1,1,0)$ & $(0,1,0)$ & $(0,1,0)$ & $(1,0,0)$ & $(1,0,0)$ & $(0,0,0)$ & $(0,0,0)$ \\
\hline$(-,+,-)$ & $\mathrm{V} 3$ & $\mathrm{~V} 4$ & $\mathrm{~V} 3$ & $\mathrm{~V} 4$ & $\mathrm{~V} 2$ & $\mathrm{~V} 0$ & $\mathrm{~V} 2$ & $\mathrm{~V} 0$ \\
& $(0,0,0)$ & $(1,0,0)$ & $(0,0,0)$ & $(1,0,0)$ & $(0,0,1)$ & $(1,0,1)$ & $(0,0,1)$ & $(1,0,1)$ \\
\hline$(-,+,+)$ & $\mathrm{V} 0$ & $\mathrm{~V} 5$ & $\mathrm{~V} 3$ & $\mathrm{~V} 4$ & $\mathrm{~V} 0$ & $\mathrm{~V} 5$ & $\mathrm{~V} 3$ & $\mathrm{~V} 4$ \\
& $(0,1,1)$ & $(0,0,1)$ & $(0,1,0)$ & $(0,0,0)$ & $(0,1,1)$ & $(0,0,1)$ & $(0,1,0)$ & $(0,0,0)$ \\
\hline$(-,-,+)$ & $\mathrm{V} 5$ & $\mathrm{~V} 5$ & $\mathrm{~V} 4$ & $\mathrm{~V} 4$ & $\mathrm{~V} 6$ & $\mathrm{~V} 6$ & $\mathrm{~V} 0$ & $\mathrm{~V} 0$ \\
& $(0,0,0)$ & $(0,0,0)$ & $(1,0,0)$ & $(1,0,0)$ & $(0,1,0)$ & $(0,1,0)$ & $(1,1,0)$ & $(1,1,0)$ \\
\hline$(+,-,+)$ & $\mathrm{V} 0$ & $\mathrm{~V} 5$ & $\mathrm{~V} 0$ & $\mathrm{~V} 5$ & $\mathrm{~V} 1$ & $\mathrm{~V} 6$ & $\mathrm{~V} 1$ & $\mathrm{~V} 6$ \\
& $(1,0,1)$ & $(0,0,1)$ & $(1,0,1)$ & $(0,0,1)$ & $(1,0,0)$ & $(0,0,0)$ & $(1,0,0)$ & $(0,0,0)$ \\
\hline$(+,-,-)$ & $\mathrm{V} 1$ & $\mathrm{~V} 6$ & $\mathrm{~V} 2$ & $\mathrm{~V} 0$ & $\mathrm{~V} 1$ & $\mathrm{~V} 6$ & $\mathrm{~V} 2$ & $\mathrm{~V} 0$ \\
& $(0,0,0)$ & $(0,1,0)$ & $(0,0,1)$ & $(0,1,1)$ & $(0,0,0)$ & $(0,1,0)$ & $(0,0,1)$ & $(0,1,1)$ \\
\hline
\end{tabular}




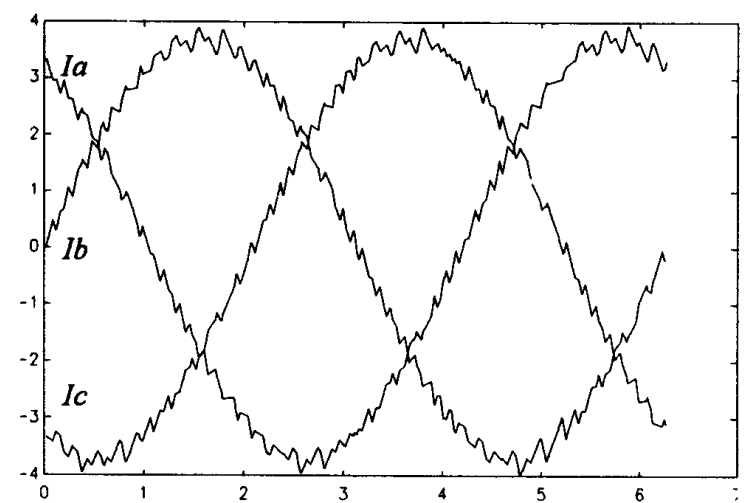

Fig. 8. Input current waveforms

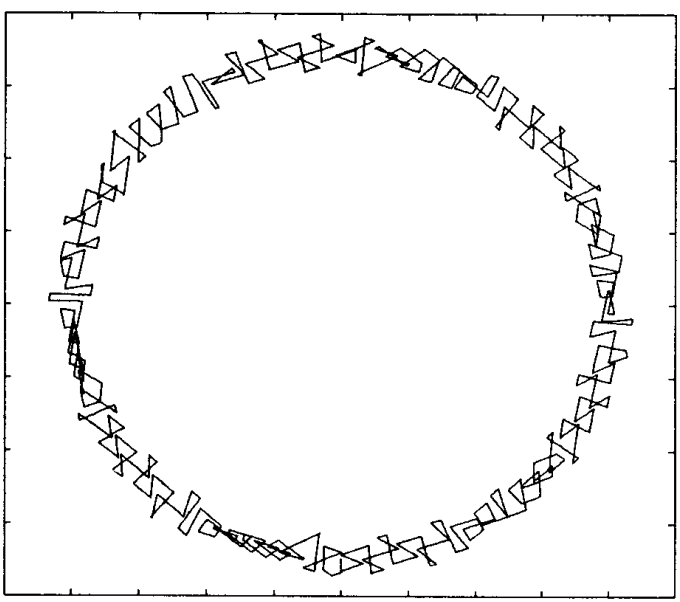

Fig. 9. Traces of the input current space vectors

\section{CONCLUSIONS}

A new three-phase boost-type PFC using AC switches is presented. The space vector modulation and hysteresis current control are adopted in the proposed control scheme. Several advantages are observed

1.)Employing three AC switches, the proposed approach makes the operational principle clear and gives the possibility of simple control design.

2.)No high-speed microprocessors or DSP chips are used.
3.) Only two of the three $\mathrm{AC}$ switches are controlled in each interval. The overall switching times is reduced by 33 percents. Switching losses are reduced.

Owing to its control simplicity and excellent performance, the proposed approach offers an attractive choice of PFC's for medium and large power applications.

\section{ACKNOWLEDGEMENTS}

The authors would like to thank the National Science Council, Taiwan, ROC for its financial assistance that enabled them to undertake this research work.

\section{REFERENCES}

[1] P.N. Enjeti and R. Martinez, "A High Performance Single Phase $\mathrm{AC}$ to $\mathrm{DC}$ Rectifier with Input Power Factor Correction," pp. 190-195, IEEE APEC'93 Conference Proceeding, 1993.

[2] S. Manias, "Novel Full Bridge Semicontrolled Switch Mode Rectifier," pp. 252-256 IEE Proceeding B, Electr. Power Appl., Vol. 138, No. 5, 1991.

[3] J.W. Dixon and B.T. Ooi, "Indirect Current Control of a Unity Power Factor Sinusoidal Current Boost Type Three-Phase Rectifier", pp. 508-515, IEEE, Trans. Ind. Elect., Vol. 35, No. 4, 1988.

[4] A.W. Green, J.T. Boys, and G.F. Gates, "3-Phase Volatge Sourced Reversible Rectifier", pp. 362-370 IEE Proceeding B, Electr. Power Appl., Vol. 135, No. 6, 1988.

[5] R. Wu, S.B. Dewan, G.R. Slemon, "A PWM AC-to-DC Converter with Fixed Switching Frequency," pp. 880-885, IEEE, Trans. Ind. Appl., Vol. IA-26, No. 2, 1990.

[6] B.T. Ooi, J.C. Salmon, J.W. Dixon, and A.B. Kulkarni, "A 3-Phase Controlled Current Converter with Leading Power Factor," pp. 78-84, IEEE, Trans. Ind. Appl., Vol. IA-23, No. 1, 1987.

[7] J.W. Dixon, A.B. Kulkarni, M. Nishimoto, and B.T. Ooi, "Characteristics of a Controlled Current PWM Rectifier Link," pp. 685-691, IEEE, IAS, Conference Proceeding, 1986.

[8] J.S. Lin, C.L. Chen, and C.Y. Lai, "A High-Bandwith PWM Servo Amplifier for the Direct-Drive-Valve Actuation System," pp. 328-332, IEEE APEC'93 Conference Proceeding, 1993. 